\title{
Contracting Fashion Products Supply Chains When Demand Is Dependent on Price and Sales Effort
}

\author{
Ying Wei and Liyang Xiong \\ School of Management, Department of Business Administration, Jinan University, Guangzhou 510632, China \\ Correspondence should be addressed to Ying Wei; yingwei@jnu.edu.cn
}

Received 15 May 2014; Revised 2 July 2014; Accepted 11 July 2014

Academic Editor: Pui-Sze Chow

Copyright (c) 2015 Y. Wei and L. Xiong. This is an open access article distributed under the Creative Commons Attribution License, which permits unrestricted use, distribution, and reproduction in any medium, provided the original work is properly cited.

\begin{abstract}
This paper investigates optimal decisions in a two-stage fashion product supply chain under two specified contracts: revenuesharing contract and wholesale price contract, where demand is dependent on retailing price and sales effort level. Optimal decisions and related profits are analyzed and further compared among the cases where the effort investment fee is determined and undertaken either by the retailer or the manufacturer. Results reveal that if the retailer determines the effort investment level, she would be better off under the wholesale price contract and would invest more effort. However, if the manufacturer determines the effort level, he prefers to the revenue-sharing contract most likely if both parties agree on consignment.
\end{abstract}

\section{Introduction}

Study in fashion products supply chains management often focuses on inventory decisions and assumes that demand is exogenously determined $[1,2]$. However, in practice retail store managers often combine marketing decisions such as retailing price and promotion level, which directly impacts consumer demands, with operational decisions like stock levels. For example, retail outlet managers take extra effort and offer discounting prices to those overstock items such as clothes and shoes. Demands are therefore regarded as endogenously determined in such supply chain systems. In particular, this paper investigates optimal decisions in fashion product supply chains where demand is endogenously dependent on both price and sales effort.

Contracts in fashion and textile supply chains exhibits different forms $[3,4]$. Although wholesale pricing contract has been and still is a dominant form, sharing revenue with partners has increasingly grown in recent years [5]. We are then interested in how contract types influence pricing and sales effort decisions of a fashion product supply chain. It is also worth noting though sales effort most often is offered by a retailer, it is still quite common that a manufacturer decides and exerts effort investment to promote sales. For example, in Gome, the giant retail outlet in consumer electronics in
China, those brand-name manufacturers train and hire sales people to promote their own products in Gome's outlets. Does it matter who takes the effort investment? If it does, will it impact the effort level as well as other supply chain decisions? In addition, under different contracting forms will the impact be different? Under which scenario, will the retailer (or the manufacturer) be better off?

This paper intends to answer these questions. In particular, the purpose of the paper is threefold: first, to investigate the impact of price and sales effort on the demand and supply chain decisions, second, to investigate the contracting form on the supply chain decisions, and third, to identify the players' optimal choice for different supply chain settings.

To study the degree of effectiveness of price and sales effort on sales depends on how these factors influence the aggregate demand. The formulation of demand function is therefore very essential. Huang et al. [6] give a comprehensive survey on demand functions in decision modeling. Here we assume a power model where both price and sales effort are endogenous decision variables. The advantage of the power model is its ability to characterize the nonlinear effects arising in the market, however, with the drawback that the demand elasticity always equals a constant. In addition, when price or sales effort approaches zero, demand approaches infinity, which is not realistic. 
Considering the complexity of the demand function, this paper confines the discussion to deterministic demand in a single manufacturer-retailer supply chain structure. Two types of contracts are considered: wholesale price contract and revenue-sharing contract. With the purpose to maximize their own profits, optimal decisions of both manufacturer and retailer are investigated and further compared where the effort investment fee determined either by the manufacturer or by the retailer. Our results reveal that (1) if the retailer decides the effort investment level, she would be better off under the wholesale price contract and would invest more effort. (2) However, if the manufacturer determines the effort level, he prefers to the revenue-sharing contract given that the effort impact factor belongs to certain specified range.

\section{Related Work}

There have been a growing number of studies investigating the impact of endogenous demand functions in recent decades. A variety of mathematical forms have been developed to characterize demand functions which depend on a firm's operational and marketing activities, see [6] for a general review. A simple classification is to divide it into deterministic demand and stochastic demand formulations.

Assuming demand is stochastic and price-sensitive, a series of work study joint pricing and inventory problems and investigates the optimal combined decisions, with [7] on single-period models and [8-11] on multiple-period models. Extending the price-sensitive demand assumption from onestage problem to supply chain structures, Chauhan and Proth [12] study the optimal decisions under a revenue-sharing contract with the purpose to maximize the total chain's net profit. Chiu et al. [13] show that for price-sensitive demand, a policy that combines the use of wholesale price, channel rebate, and returns can coordinate a supply chain channel. Assuming demand is deterministic and price-dependent, some study in joint inventory and pricing problem is based on linear demand models $[14,15]$, while others on power models [16]. Conducting a two-stage fashion supply chain with riskaverse retailer and price-dependent demand, $\mathrm{Xu}$ et al. [3] discuss revenue sharing contract and two-part tariff contract and further explores the optimal conditions for coordination.

Typical work assuming demand is dependent on sales effort can be referred to [17-19]. Taylor [17] studies supply chain coordination considering the impact of sales effort on the demand under channel rebates. Zhang and Chen [18] investigate different forms of contract with effort-dependent demand. Chiu et al. [4] explore the performance of sales rebate contract in fashion supply chains via a mean-variance framework. Further noticing the impact of both price and sales effort, He et al. [19] study the coordination of supply chains.

Some work incorporates other marketing decisions like advertising and display level into operational models and study the combined impact on demand function. It should be noted that because of the complexity of the demand function, mostly demand is assumed to be deterministic. Assuming demand is deterministic and a power function of pricing and advertisement decisions, Yue et al. [20] study the optimal marketing decisions in a manufacturer-retailer supply chain, and compares the results between a Stackelberg and a Nash game setting. Wang and $\mathrm{Hu}$ [21] study capital allocation's selection effect and investment efficiency problem, assuming demand is a deterministic power function depending on price and investment level. Cao and Zhou [22] find that quantity discounting contract can coordinate the supply chain given demand is deterministic and influenced by both price and stock level.

This paper extends the exogenous demand assumption to endogenous demand incorporating price and sales effort decisions in a supply chain system, where demand is assumed to be a deterministic power function following [20-22]. It contributes to the literature by discussing and comparing optimal decisions under different contracting form in the supply chain. In addition, it jointly considers supply chain decisions and marketing decisions, whoever decides and undertakes the sales effort investment level really depends on supply chain partners' bargain power in the market.

\section{The Model}

We first describe a base model under a wholesale price contract structure. In a two-stage supply chain system, a risk neutral manufacturer supplies a product to a single riskneutral retailer. Let $w>0$ denote the wholesale price and let $c>0$ denote the unit production cost. The retailer decides the retailing price $p>0$ and effort investment level $e$. Here the effort could be advertising, effort of sales people, and display effort to promote products, and so forth. Demand is a continuous variable dependent on retailing price and effort investment level. More specifically, let demand $D=k p^{-\alpha} e^{\beta}$, where $k>0$ is the potential market size. $\alpha$ is the price impact factor, with $\alpha>1$ implying that demand is sensitive to the price, while $0<\alpha \leq 1$ implying that demand is insensitive to the price. Following the standard assumption as mentioned in [3], here we assume $\alpha>1$. Similarly, $\beta$ is the impact factor of effort investment level. In addition, we assume that demand increases with the effort investment level, while at a decreasing rate, that is, $0<\beta<1$ [14].

Employing a wholesale price contract, the game's timing is as follows. The manufacturer first sets a wholesale price, $w$. The retailer then decides the retailing price and effort investment level, orders $q \geq 0$ units of inventory and pays the manufacturer $w q$. Noticing that demand is deterministic, we have $q=D=k p^{-\alpha} e^{\beta}$. Assuming that order-fulfillment time is zero and there is no production capacity constraint, the manufacturer then immediately supplies $q$ units to the retailer to satisfy her customer. The net profit of the retailer, $\pi_{r}$, and the net profit of the manufacturer, $\pi_{m}$, separately are

$$
\begin{gathered}
\pi_{r}^{W, R}=D(p-w)-e=k \cdot p^{-\alpha} \cdot e^{\beta} \cdot(p-w)-e, \\
\pi_{m}^{W, R}=D \cdot(w-c) .
\end{gathered}
$$

Here the first superscript " $W / R$ " denotes for "wholesale price/revenue-sharing contract," the second superscript " $R / M$ " denote for "retailer/manufacturer decides the effort investment". 
Under a revenue sharing contract, when the retailer decides the effort investment level, the game's timing is as follows. The manufacturer first sets a wholesale price, $w$, and revenue sharing ratio $\lambda$. The retailer then decides the retailing price and effort investment level, orders $q \geq 0$ units of inventory and pays the manufacturer $w q$. Similarly, $q=D$. The net profits of both the retailer and the manufacturer are

$$
\begin{gathered}
\pi_{r}^{R, R}=D(\lambda \cdot p-w)-e=(\lambda \cdot p-w) \cdot k \cdot p^{-\alpha} \cdot e^{\beta}-e, \\
\pi_{m}^{R, R}=D \cdot[(1-\lambda) \cdot p+w-c] .
\end{gathered}
$$

Under a wholesale price contract, however, if the manufacturer determines and undertakes the effort investment (like P\&G, as a manufacturer, decides its advertising investment for Panteen shampoo), the manufacturer first sets a wholesale price, $w$, and decides the effort investment level, $e$. The retailer then decides the retailing price and orders $q \geq 0$ units of inventory and pays the manufacturer $w q$, where $q=$ $D$. The net profits of both the retailer and the manufacturer are

$$
\begin{gathered}
\pi_{r}^{W, M}=D(p-w)=k \cdot p^{-\alpha} \cdot e^{\beta} \cdot(p-w), \\
\pi_{m}^{W, M}=D \cdot(w-c)-e .
\end{gathered}
$$

Under a revenue-sharing contract, if the manufacturer determines the effort investment level $e$, we revise the model setting as follows. Instead of offering a wholesale price $w$, the manufacturer asks the retailer to sell on consignment. The retailer decides the revenue sharing ratio $\lambda$ and the retailing price $p$. The net profits of the retailer and the manufacturer are then

$$
\begin{gathered}
\pi_{r}^{R, M}=D \cdot \lambda \cdot p, \\
\pi_{m}^{R, M}=D[(1-\lambda) \cdot p-c]-e .
\end{gathered}
$$

In what follows, we will first discuss the optimal supply chain decisions under the aforementioned settings, and then compare them for different scenarios.

\section{Optimal Decisions If Retailer Determines the Effort}

4.1. Under a Wholesale Price Contract. Given a wholesale price $w$, the retailer decides optimal decisions on the retailing price $p$ and the effort investment $e$ to maximize (1). Taking first order derivative on (1) yields

$$
\begin{gathered}
\frac{\partial \pi_{r}^{W, R}}{\partial p}=-\alpha \cdot k \cdot p^{-\alpha-1} \cdot e^{\beta} \cdot(p-w)+k \cdot p^{-\alpha} \cdot e^{\beta}=0, \\
\frac{\partial \pi_{r}^{W, R}}{\partial e}=\beta \cdot k \cdot p^{-\alpha} \cdot e^{\beta-1}(p-w)-1=0 .
\end{gathered}
$$

Solving the above equations, we obtain the optimal price $p_{W, R}^{*}=\alpha w /(\alpha-1)$ and the optimal effort $e_{W, R}^{*}=$ $\left[((\beta \cdot k) /(\alpha-1)) \cdot(\alpha /(\alpha-1))^{-\alpha}\right]^{1 /(1-\beta)} \cdot w^{(1-\alpha) /(1-\beta)}$.

The manufacturer then decides the optimal wholesale price $w_{W, R}^{*}$ to maximize his profit (see (2)). Proposition 1 summarizes the optimal decisions of both the manufacturer and the retailer.
Proposition 1. (i) $w_{W, R}^{*}=((\alpha-\beta) /(\alpha-1)) \cdot c$; (ii) $p_{W, R}^{*}=$ $(\alpha /(\alpha-1)) \cdot((\alpha-\beta) /(\alpha-1)) \cdot c$; $($ iii $) e_{W, R}^{*}=[((\beta \cdot k) /(\alpha-1))$. $\left.(\alpha /(\alpha-1))^{-\alpha}\right]^{1 /(1-\beta)} \cdot c^{(1-\alpha) /(1-\beta)} \cdot((\alpha-\beta) /(\alpha-1))^{(1-\alpha) /(1-\beta)}$.

Proof. (i) Substituting $e_{W, R}^{*}=[((\beta \cdot k) /(\alpha-1)) \cdot(\alpha /(\alpha-$ $\left.1))^{-\alpha}\right]^{1 /(1-\beta)} \cdot w^{(1-\alpha) /(1-\beta)}$ and $D=e /(\beta \cdot(p-w))=(e \cdot(\alpha-1)) /$ $(\beta \cdot w)$ into (2) and taking first order optimal equation yields

$$
\begin{aligned}
\frac{\partial \pi_{m}^{W, R}}{\partial w}= & \frac{c}{w^{2}} \cdot \frac{\alpha-1}{\beta} \cdot A \cdot w^{(1-\alpha) /(1-\beta)}+\frac{\alpha-1}{\beta} \cdot\left(1-\frac{c}{w}\right) \\
& \cdot A \cdot \frac{1-\alpha}{1-\beta} \cdot w^{((1-\alpha) /(1-\beta))-1}=0,
\end{aligned}
$$

where $A=\left[((\beta \cdot k) /(\alpha-1)) \cdot(\alpha /(\alpha-1))^{-\alpha}\right]^{1 /(1-\beta)}$. We then have $w_{W, R}^{*}=((\alpha-\beta) /(\alpha-1)) \cdot c$, verifying (i).

(ii)-(iii) Substituting $w_{W, R}^{*}$ back to $p_{W, R}^{*}$ and $e_{W, R}^{*}$, (ii) and (iii) can then be easily proved.

Based on the results of Proposition 1, we can then calculate profits of both the retailer and the manufacturer, as summarized in Table 1.

4.2. Under a Revenue-Sharing Contract. Given a revenuesharing contract $\{w, \lambda\}$, the retailer decides her optimal decisions on $p$ and $e$ to maximize (3), while the manufacturer decides his optimal decisions on $w$ and $\lambda$ to maximize (4). Proposition 2 summarizes related results.

Proposition 2. (i) $w_{R, R}^{*}=\beta c$; (ii) $\lambda_{R, R}^{*}=\beta$ (iii) $p_{R, R}^{*}=\alpha c$ l $(\alpha-1)$; (iv) $e_{R, R}^{*}=\left[((\beta \cdot k) /(\alpha-1)) \cdot(\alpha /(\alpha-1))^{-\alpha}\right]^{1 /(1-\beta)}$. $c^{(1-\alpha) /(1-\beta)} \cdot \beta^{1 /(1-\beta)}$.

Proof. The first order optimal equation of (3) yields $p_{R, R}^{*}=$ $(\alpha \cdot w) /((\alpha-1) \cdot \lambda)$ and $e_{R, R}^{*}=[((\beta \cdot k) /(\alpha-1)) \cdot(\alpha /$ $\left.(\alpha-1))^{-\alpha}\right]^{1 /(1-\beta)} \cdot w^{(1-\alpha) /(1-\beta)} \cdot \lambda^{\alpha /(1-\beta)}$

Substituting them back to (4), and then taking first order derivative, we have

$$
\begin{aligned}
\frac{\partial \pi_{m}^{R, R}}{\partial \lambda}= & \frac{-\alpha}{\lambda^{2} \cdot(\alpha-1)} \cdot \frac{\alpha-1}{\beta} \cdot A \cdot w^{(1-\alpha) /(1-\beta)} \cdot \lambda^{\alpha /(1-\beta)} \\
& +\left(\frac{\alpha}{(\alpha-1) \cdot \lambda}-\frac{1}{\alpha-1}-\frac{c}{w}\right) \cdot \frac{\alpha-1}{\beta} A \cdot \frac{\alpha}{1-\beta} \\
& \cdot w^{(1-\alpha) /(1-\beta)} \cdot \lambda^{(\alpha /(1-\beta))-1}=0, \\
\frac{\partial \pi_{m}^{R, R}}{\partial w}= & \frac{c}{w^{2}} \cdot \frac{\alpha-1}{\beta} A \cdot w^{(1-\alpha) /(1-\beta)} \cdot \lambda^{\alpha /(1-\beta)} \\
& +\left(\frac{\alpha}{(\alpha-1) \cdot \lambda}-\frac{1}{\alpha-1}-\frac{c}{w}\right) \cdot \frac{\alpha-1}{\beta} A \\
& \cdot \frac{1-\alpha}{1-\beta} \cdot w^{((1-\alpha) /(1-\beta))-1} \cdot \lambda^{\alpha /(1-\beta)}=0 .
\end{aligned}
$$

Solving the above equations yields $w_{R, R}^{*}=\beta c$ and $\lambda_{R, R}^{*}=$ $\beta$. Substituting them back to $p_{R, R}^{*}$ and $e_{R, R}^{*}$, (i)-(iv) are then proved. 


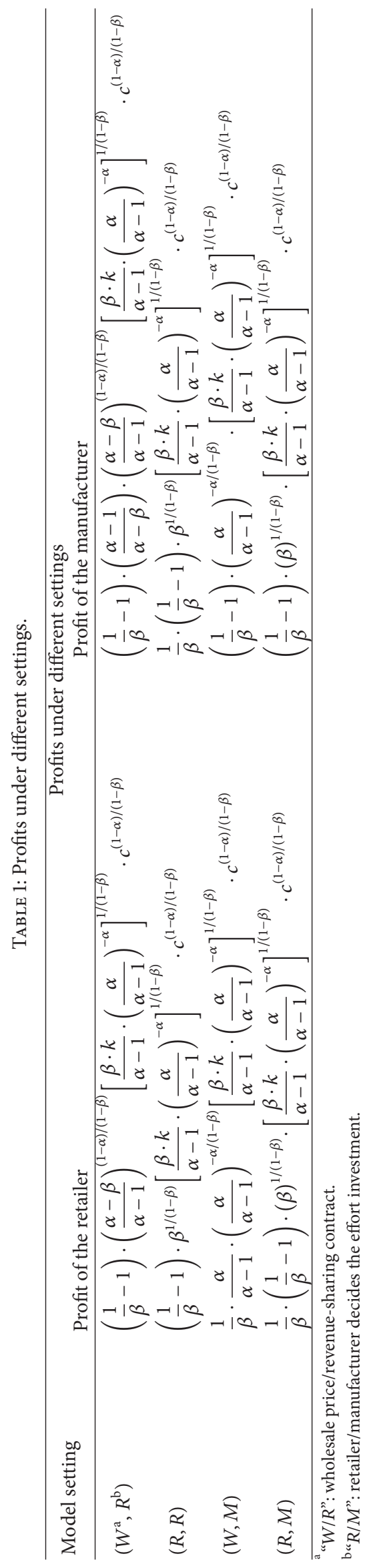


Similarly, we can then calculate profits of both the retailer and the manufacturer, summarized in Table 1.

4.3. Comparison. Comparing the optimal decisions and profits between the above two settings, we have the following results.

Theorem 3. (i) $p_{W, R}^{*}>p_{R, R}^{*}$; (ii) $e_{W, R}^{*}>e_{R, R}^{*}$; (iii) $\pi_{r}^{W, R}>$ $\pi_{r}^{R, R}$.

Proof. (i) From Propositions 1 and 2, we have $p_{W, R}^{*} / p_{R, R}^{*}=$ $(\alpha-\beta) /(\alpha-1)$. Noticing $\alpha>1$ and $0<\beta<1$, easily we have $(\alpha-\beta) /(\alpha-1)>1$, thus, (i) is proved.

(ii) Notice $e_{W, R}^{*} / e_{R, R}^{*}=\left[((\alpha-1) /(\alpha-\beta))^{\alpha-1} \cdot(1 /\right.$ $\beta)]^{1 /(1-\beta)}$, and $1 /(1-\beta)>1$. To show $e_{W, R}^{*} / e_{R, R}^{*}>1$, it is equivalently to show $\ln \left[((\alpha-1) /(\alpha-\beta))^{\alpha-1} \cdot(1 / \beta)\right]>0$.

Let $f(\alpha, \beta)=(\alpha-1) \cdot[\ln (\alpha-1)-\ln (\alpha-\beta)]-\ln \beta$, since $\partial f(\alpha, \beta) / \partial \beta=(\alpha-1) /(\alpha-\beta)-1 / \beta=(\alpha \cdot(\beta-1)) /(\beta \cdot(\alpha-\beta))<$ $0, f(\alpha, \beta)$ decreases in $\beta$. Thus, $f(\alpha, \beta)>f(\alpha, 1)=0$.

Similarly, we have $\partial f(\alpha, \beta) / \partial \alpha=[\ln (\alpha-1)-\ln (\alpha-\beta)]+$ $(\alpha-1) \cdot(1 /(\alpha-1)-1 /(\alpha-\beta))=\ln ((\alpha-1) /(\alpha-\beta))-(\alpha-1) /$ $(\alpha-\beta)+1$.

Let $x=(\alpha-1) /(\alpha-\beta)$, obviously $x \in(0,1)$ and $x$ increases in $\alpha$. Let $f(x)=\ln x-x+1$, since $\partial f(x) / \partial x=1 / x-1>0$, then $f(x)$ increases in $x$, and $f(x)<f(1)=0$. Therefore $\partial f(\alpha, \beta) / \partial \alpha<0$, and $f(\alpha, \beta)$ decrease in $\alpha$.

As $\alpha \rightarrow \infty,((\alpha-1) /(\alpha-\beta))^{\alpha-1}=e^{\beta-1}, f(\alpha, \beta)=$ $\ln \left(e^{\beta-1} / \beta\right)$. Notice that $f(\alpha, \beta)$ decreases in $\beta$, and $f(\infty, \beta)>$ $f(\infty, 1)=0$, therefore, $f(\alpha, \beta)>f(\infty, \beta)>0$. Thus, $e_{W, R}^{*} / e_{R, R}^{*}>1$ holds. (ii) is then proved.

(iii) Noticing $\pi_{r}^{W, R} / \pi_{r}^{R, R}=\left[((\alpha-1) /(\alpha-\beta))^{\alpha-1} /\right.$ $\beta]^{1 /(1-\beta)}$. Following the same prove process as in (ii), thus $\pi_{r}^{W, R} / \pi_{r}^{R, R}>1$

Remark 4. When the retailer determines and undertakes the effort investment, the optimal wholesale price and retailing price are higher under wholesale price. So is the effort investment level. As a payback, the retailer betters off under a wholesale price contract. Theorem 3 also implies that the retailer has no intension to carry out revenue-sharing contract if she has to undertake the effort investment.

\section{Optimal Decisions If Manufacturer Determines the Effort}

5.1. Under a Wholesale Price Contract. Given a wholesale price $w$, and the determined effort investment $e$, the retailer decides optimal retailing price $p$ to maximize (5). The first order optimality of (5) yields $p_{W, M}^{*}=(\alpha \cdot w) /(\alpha-1)$. The manufacturer then decides the optimal $w$ and $e$ to maximize (6). Proposition 5 summarizes the optimal decisions.

Proposition 5. (i) $p_{W, M}^{*}=\left(\alpha^{2} /(\alpha-1)^{2}\right) \cdot c$; (ii) $w_{W, M}^{*}$ $=(\alpha /(\alpha-1)) \cdot c$; (iii) $e_{W, M}^{*}=[((\beta \cdot k) /(\alpha-1)) \cdot(\alpha /$ $\left.(\alpha-1))^{-\alpha}\right]^{1 /(1-\beta)} \cdot c^{(1-\alpha) /(1-\beta)} \cdot(\alpha /(\alpha-1))^{-\alpha /(1-\beta)}$.
Proof. Substituting $p_{W, M}^{*}=(\alpha \cdot w) /(\alpha-1)$ into (6) obtains

$$
\begin{aligned}
\pi_{m}^{W, M} & =D \cdot(w-c)-e \\
& =k \cdot\left(\frac{\alpha}{\alpha-1}\right)^{-\alpha} \cdot w^{-\alpha} \cdot e^{\beta} \cdot(w-c)-e .
\end{aligned}
$$

Taking its first order optimality equation yields

$$
\begin{aligned}
\frac{\partial \pi_{m}^{W, M}}{\partial w}= & k \cdot\left(\frac{\alpha}{\alpha-1}\right)^{-\alpha} \cdot(-\alpha) \cdot w^{-\alpha-1} \cdot e^{\beta} \cdot(w-c) \\
& -k \cdot\left(\frac{\alpha}{\alpha-1}\right)^{-\alpha} \cdot w^{-\alpha} \cdot e^{\beta}=0 \\
\frac{\partial \pi_{m}^{W, M}}{\partial e}= & k \cdot\left(\frac{\alpha}{\alpha-1}\right)^{-\alpha} \cdot \beta \cdot w^{-\alpha} \cdot e^{\beta-1} \\
& \cdot(w-c)-1=0 .
\end{aligned}
$$

Solving the above equations obtains $w_{W, M}^{*}=(\alpha /(\alpha-$ $1)) \cdot c$ and $e_{W, M}^{*}=\left[((\beta \cdot k) /(\alpha-1)) \cdot(\alpha /(\alpha-1))^{-\alpha}\right]^{1 /(1-\beta)}$. $c^{(1-\alpha) /(1-\beta)} \cdot(\alpha /(\alpha-1))^{-\alpha /(1-\beta)}$. Thus, (ii) and (iii) are proved. Substituting $w_{W, M}^{*}$ into $p_{W, M}^{*}=(\alpha \cdot w) /(\alpha-1)$, we can then easily prove (i).

Profits of both the retailer and the manufacturer are calculated and listed in Table 1.

5.2. Under a Revenue-Sharing Contract on Consignment. Under a revenue-sharing contract on consignment, the retailer decides the revenue sharing ratio $\lambda$ and the selling price $p$ to maximize (7), while the manufacturer decides the effort investment $e$ to maximize (8). Proposition 6 summarizes the related results.

Proposition 6. (i) $p_{R, M}^{*}=(\alpha \cdot c) /(\alpha-1)$; (ii) $\lambda_{R, M}^{*}=$ $(1-\beta) / \alpha$; $($ iii $) e_{R, M}^{*}=\left[((\beta \cdot k) /(\alpha-1)) \cdot(\alpha /(\alpha-1))^{-\alpha}\right]^{1 /(1-\beta)}$. $c^{(1-\alpha) /(1-\beta)} \cdot(\beta)^{1 /(1-\beta)}$.

Proof. Taking the first order derivative on (8) and sets to be zero obtains

$$
\frac{\partial \pi_{m}^{R, M}}{\partial e}=[(1-\lambda) \cdot p-c] \cdot k \cdot p^{-\alpha} \cdot \beta \cdot e^{\beta-1}-1=0 .
$$

Solving the equation yields $e_{R, M}^{*}=[\beta \cdot k]^{1 /(1-\beta)}$. $[(1-\lambda) \cdot p-c]^{1 /(1-\beta)} \cdot p^{-\alpha /(1-\beta)}$. Substituting it back to $(7)$ and taking the first order optimality equation yields

$$
\begin{aligned}
\frac{\partial \pi_{r}^{R, M}}{\partial p}= & \frac{1-\alpha-\beta}{1-\beta} \cdot B \cdot[(1-\lambda) \cdot p-c]^{\beta /(1-\beta)} \\
& \cdot p^{((1-\alpha-\beta) /(1-\beta))-1}+B \cdot(1-\lambda) \\
& \cdot[(1-\lambda) \cdot p-c]^{(\beta /(1-\beta))-1} \\
& \cdot p^{(1-\alpha-\beta) /(1-\beta)}=0,
\end{aligned}
$$

where $B=\lambda \cdot k \cdot[\beta \cdot k]^{\beta /(1-\beta)}$. 


$$
\begin{aligned}
\frac{\partial \pi_{r}^{R, M}}{\partial \lambda}= & k \cdot[\beta \cdot k]^{\beta /(1-\beta)} \cdot[(1-\lambda) \cdot p-c]^{\beta /(1-\beta)} \\
& \cdot p^{(1-\alpha-\beta) /(1-\beta)}-\frac{\beta}{1-\beta} \cdot p \cdot \lambda \cdot k \cdot[\beta \cdot k]^{\beta /(1-\beta)} \\
& \cdot[(1-\lambda) \cdot p-c]^{(\beta /(1-\beta))-1} \cdot p^{(1-\alpha-\beta) /(1-\beta)}=0 .
\end{aligned}
$$

Solving the above equations obtains $p_{R, M}^{*}=(\alpha \cdot c) /(\alpha-1)$ and $\lambda_{R, M}^{*}=(1-\beta) / \alpha$; thus, (i)-(ii) are proved.

Substituting them back to $e_{R, M}^{*}$ and then (iii) is proved.

Profits of both the retailer and the manufacturer are listed in Table 1.

5.3. Comparison. Comparing the optimal decisions and profits between the above two setting, we have the following theorem.

Theorem 7. (i) $p_{W, M}^{*}>p_{R, M}^{*}$; (ii) when $1 / e_{0} \leq \beta<1$, where $e_{0}$ is the irrational number and $e_{0} \approx 2.71828$, we have $e_{R, M}^{*}>$ $e_{W, M}^{*}$, in addition, $\pi_{m}^{R, M}>\pi_{m}^{W, M}$.

Proof. (i) From above discussions we have $p_{W, M}^{*} / p_{R, M}^{*}=$ $\alpha /(\alpha-1)$. Notice $\alpha>1$, thus, (i) holds.

(ii) Notice $e_{R, M}^{*} / e_{W, M}^{*}=\left[\beta \cdot(\alpha /(\alpha-1))^{\alpha}\right]^{1 /(1-\beta)}$. Let $f(\alpha)=(\alpha /(\alpha-1))^{\alpha}=(1+1 /(\alpha-1))^{\alpha}$. Notice that $f(\alpha)$ is a decreasing function, in addition, as $\alpha \rightarrow \infty, f(\alpha)=e_{0}$, where $e_{0}$ is the irrational number and $e_{0} \approx 2.71828$. Thus, if defining $f(\alpha, \beta)=\beta \cdot(\alpha /(\alpha-1))^{\alpha}$, for $\alpha>1, f(\alpha, \beta)>$ $f(\infty, \beta)=\beta e_{0}$. If $1>\beta>1 / e_{0}$, then $e_{R, M}^{*} / e_{W, M}^{*}=$ $\left[\beta \cdot(\alpha /(\alpha-1))^{\alpha}\right]^{1 /(1-\beta)}>1$, thus, proved.

Similarly, from Table $1, \pi_{R, M}^{*} / \pi_{W, M}^{*}=[\beta \cdot(\alpha /(\alpha-$ $\left.1)^{\alpha}\right]^{1 /(1-\beta)}$, following the same proof process, If $1>\beta>1 / e_{0}$, $\pi_{R, M}^{*} / \pi_{W, M}^{*}>1$ holds.

Remark 8. When the manufacturer determines and undertakes the effort investment, the optimal retailing price is higher under wholesale price. If the effort impact parameter $\beta$ is in a certain range $\left(1 / e_{0} \leq \beta<1\right)$, the effort investment level under the revenue sharing contract is higher, as a payback, the manufacturer betters off as compared to the wholesale pricing contract. However, it is difficult to tell which contract benefits the manufacturer if $\beta$ in the range of $0<\beta<1 / e_{0}$.

\section{Conclusions}

This paper studies a single manufacturer-retailer supply chain under different contract settings. Optimal decisions under revenue-sharing contract and wholesale price contract are analyzed and compared. If the effort investment level is determined and undertaken by the retailer, under wholesale price contract, she faces a higher wholesale price, which results in a higher retailing price and larger effort investment. As a payback, the retailer is better off. If the manufacturer determines and undertakes the effort investment, under the wholesale price contract, the retailing price is higher, while the effort investment is lower if the impact parameter $\beta$ satisfies $1 / e_{0} \leq \beta<1$. The manufacturer would be better off under a revenue-sharing contract if both parties agree on consignment.

Finally, some limitations of this paper should be pointed out. First, we only consider deterministic demand function, which limits its application in practice considering the random nature of demand variables. Second, we only discuss the optimal decisions under different supply chain contract and sales effort investment settings. Whether such contracts coordinate the supply chain or not is out of our discussion, which, however, is worthy of exploring in the future.

\section{Conflict of Interests}

The authors declare that there is no conflict of interests regarding the publication of this paper.

\section{Acknowledgments}

The authors would like to thank the support by NSFC (Projects 71101063 and 71171085). The work is also supported by Scientific Research Foundation for Returned Scholars, Ministry of Education of China, Jinan University Management School Funding Program, and Institute of Enterprise Development of Jinan University.

\section{References}

[1] G. P. Cachon, "Supply chain coordination with contracts," in Handbooks in Operations Research and Management Science, Supply Chain Management: Design Coordination and Operation, A. G. de Kok and S. C. Graves, Eds., vol. 11, pp. 229-340, Elsevier, Amsterdam, The Netherlands, 2003.

[2] Y. Wei and T.-M. Choi, "Mean-variance analysis of supply chains under wholesale pricing and profit sharing schemes," European Journal of Operational Research, vol. 204, no. 2, pp. 255-262, 2010.

[3] M. Xu, Q. Wang, and L. Ouyang, "Coordinating contracts for two-stage fashion supply chain with risk-averse retailer and price-dependent demand," Mathematical Problems in Engineering, vol. 2013, Article ID 259164, 12 pages, 2013.

[4] C.-H. Chiu, T.-M. Choi, H.-T. Yeung, and Y. Zhao, "Sales rebate contracts in fashion supply chains," Mathematical Problems in Engineering, vol. 2012, Article ID 908408, 19 pages, 2012.

[5] "Revenue sharing model in retail industry to grow," 2009, http://www.livemint.com/Companies/07Izf0Xu24ubQwgwI7iFUO/Revenue-sharing-model-in-retail-industry-to-grow.html.

[6] J. Huang, M. Leng, and M. Parlar, "Demand functions in decision modeling: a comprehensive survey and research directions," Decision Sciences, vol. 44, no. 3, pp. 557-609, 2013.

[7] N. C. Petruzzi and M. Dada, "Pricing and the newsvendor problem: a review with extensions," Operations Research, vol. 47, no. 2, pp. 183-194, 1999.

[8] A. Federgruen and A. Heching, "Combined pricing and inventory control under uncertainty," Operations Research, vol. 47, no. 3, pp. 454-475, 1999.

[9] X. Chen and D. Simchi-Levi, "Coordinating inventory control and pricing strategies with random demand and fixed ordering 
cost: the finite horizon case," Operations Research, vol. 52, no. 6 , pp. 887-896, 2004.

[10] X. Chen and D. Simchi-Levi, "Coordinating inventory control and pricing strategies with random demand and fixed ordering cost: the infinite horizon case," Mathematics of Operations Research, vol. 29, no. 3, pp. 698-723, 2004.

[11] Y. Wei, "Optimization and optimality of a joint pricing and inventory control policy in periodic-review systems with lost sales," OR Spectrum, vol. 34, no. 1, pp. 243-271, 2012.

[12] S. S. Chauhan and J.-M. Proth, "Analysis of a supply chain partnership with revenue sharing," International Journal of Production Economics, vol. 97, no. 1, pp. 44-51, 2005.

[13] C.-H. Chiu, T.-M. Choi, and C. S. Tang, "Price, rebate, and returns supply contracts for coordinating supply chains with price-dependent demands," Production and Operations Management, vol. 20, no. 1, pp. 81-91, 2011.

[14] E. S. Mills, "Uncertainty and price theory," The Quarterly Journal of Economics, vol. 73, no. 1, pp. 116-130, 1959.

[15] J. Eliashberg and R. Steinberg, "Marketing-production decisions in an industrial channel of distribution," Management Science, vol. 33, no. 8, pp. 981-1000, 1987.

[16] S. Karlin and C. R. Carr, "Prices and optimal inventory policy," in Studies in Applied Probability and Management Science, K. J. Arrow, S. Karlin, and H. Scarf, Eds., pp. 159-172, Stanford University Press, Stanford, Calif, USA, 1962.

[17] T. A. Taylor, "Supply chain coordination under channel rebates with sales effort effects," Management Science, vol. 48, no. 8, pp. 992-1007, 2002.

[18] J.-L. Zhang and J. Chen, "A coordinating contract of supply chain with sale-effort dependent demand," Chinese Journal of Management Science, vol. 12, no. 4, pp. 50-56, 2004.

[19] Y. He, X. Zhao, L. Zhao, and J. He, "Coordinating a supply chain with effort and price dependent stochastic demand," Applied Mathematical Modelling, vol. 33, no. 6, pp. 2777-2790, 2009.

[20] J. Yue, J. Austin, Z. Huang, and B. Chen, "Pricing and advertisement in a manufacturer-retailer supply chain," European Journal of Operational Research, vol. 231, no. 2, pp. 492-502, 2013.

[21] S.-J. Wang and Q.-Y. Hu, "Business models for 3C retailers: interactions of sales promotion and trade schemes," Journal of Management Science in China, vol. 14, no. 4, pp. 1-11, 2011.

[22] Z.-H. Cao and Y.-W. Zhou, "Quantity discount pricing model with demand influenced by inventory and price in supply chain," Journal of Systems Engineering, vol. 23, no. 1, pp. 67-73, 2008. 


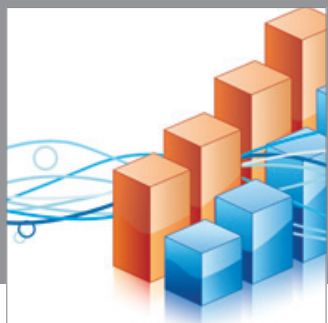

Advances in

Operations Research

mansans

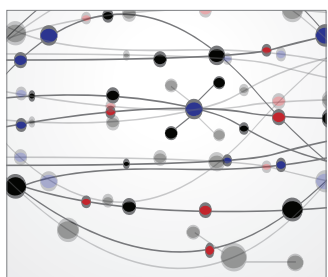

The Scientific World Journal
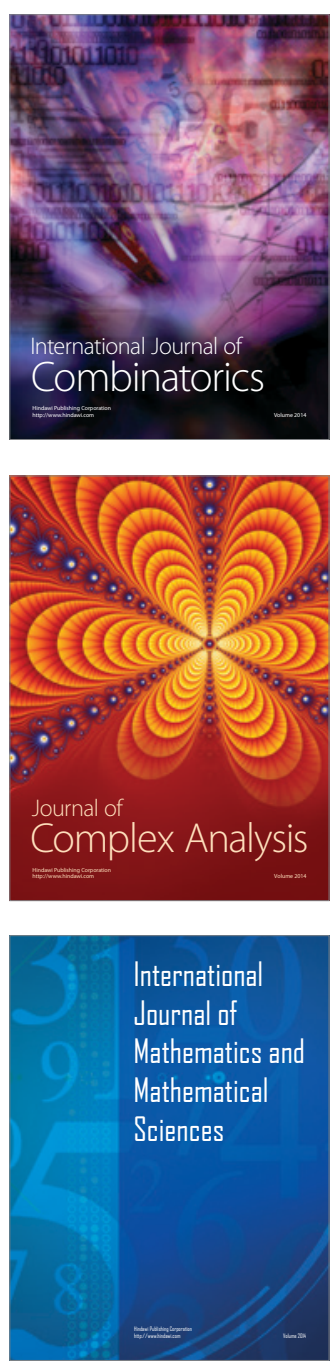
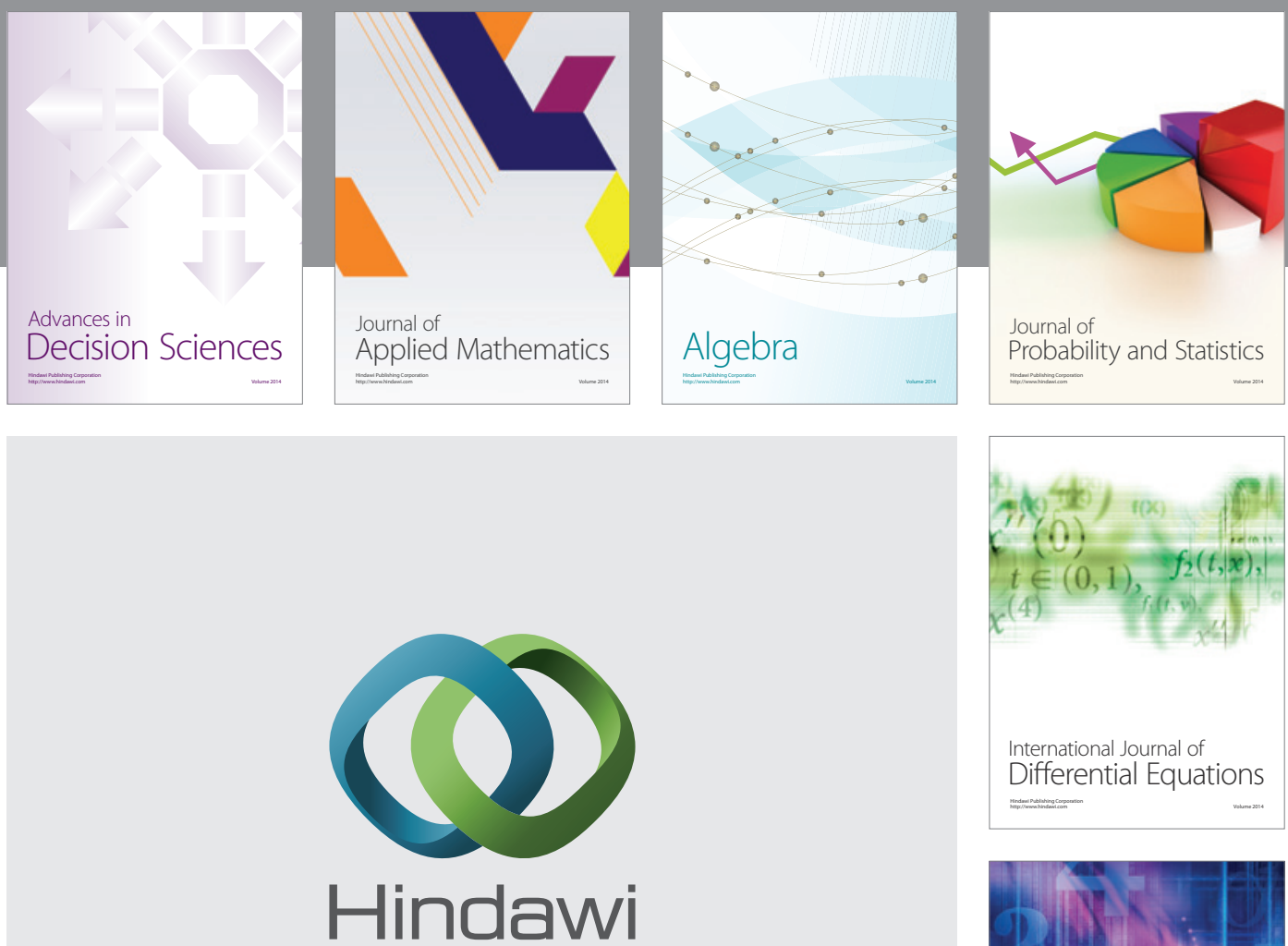

Submit your manuscripts at http://www.hindawi.com
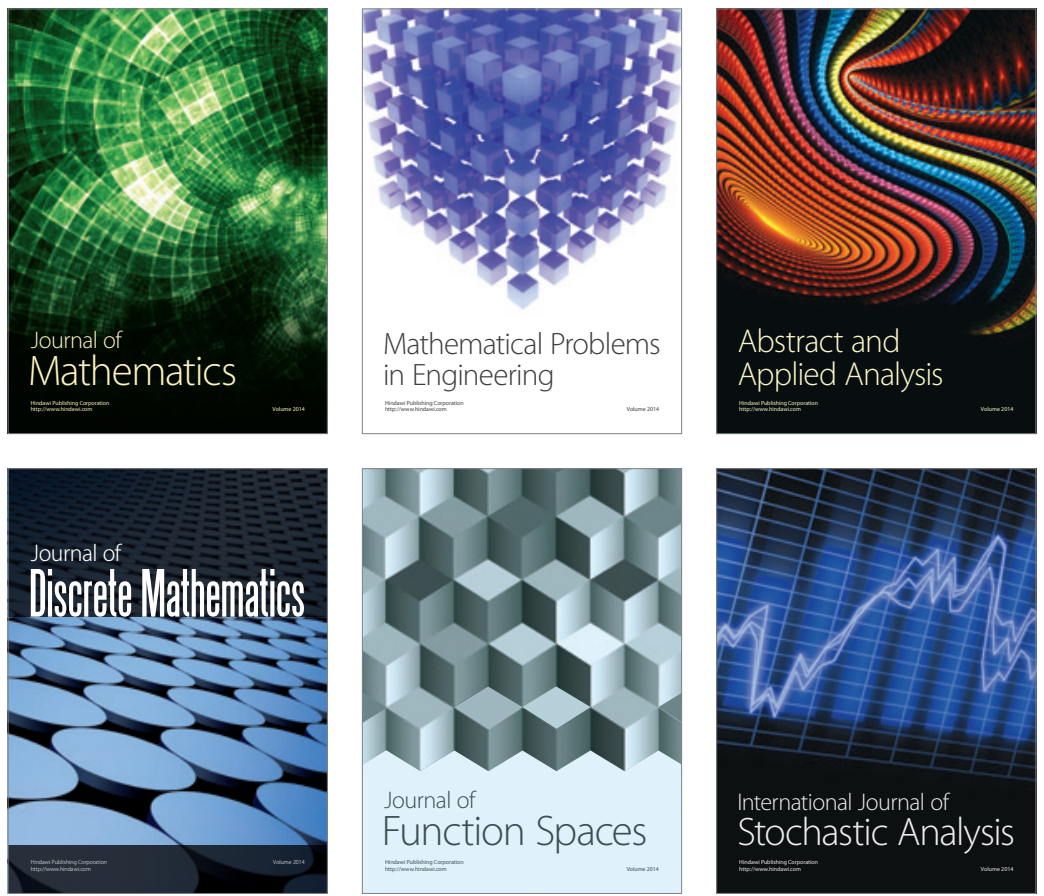

Journal of

Function Spaces

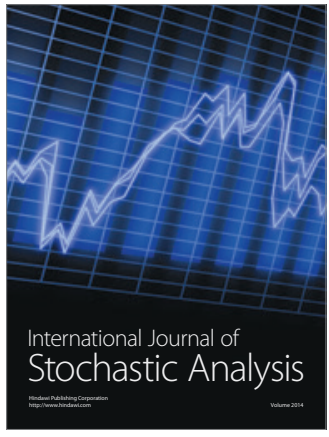

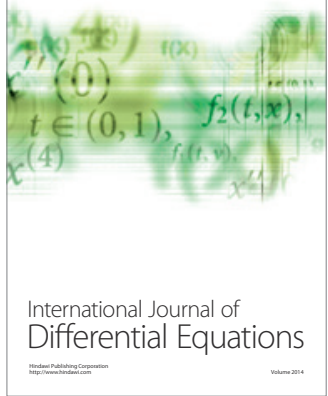
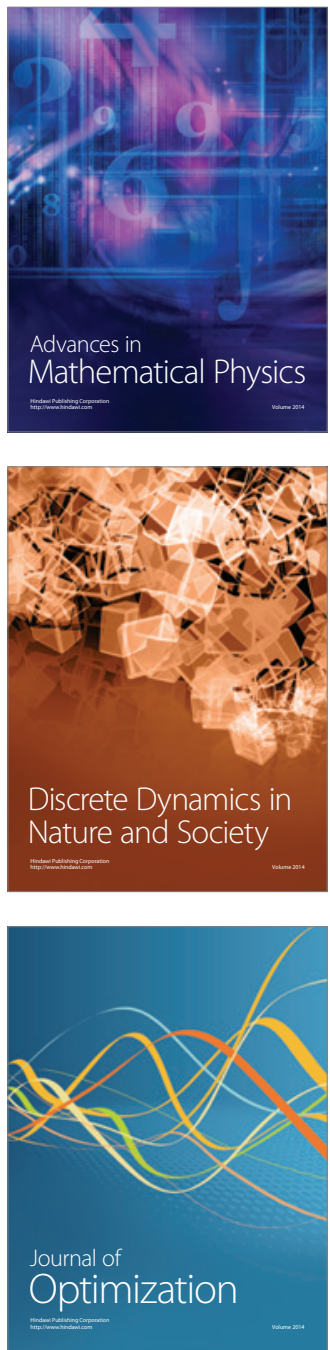